\title{
Neoliberalismo, globalización y filosofía social
}

\author{
ADOLFO GARCÍA DE LA SIENRA \\ Facultad de Economía \\ Universidad Veracruzana \\ asienra@uv.mx
}

\begin{abstract}
Resumen: Este trabajo empieza mostrando que la utopía, la cual no es más que una representación imaginaria de una sociedad en la que se habría realizado el ideal humanista secular de la personalidad libre y autónoma, es inviable y necesaria como criterio direccional para la crítica del proceso de globalización. Introduce en segundo término una concepción filosófica que reconoce la nomicidad del mundo (su sujeción a leyes naturales y normas supraarbitrarias de diferentes tipos), para mostrar que el proceso de integración mundial está impulsando por dicha nomicidad, si bien distorsionado debido a una relativa desobediencia a la misma. Concluye con una apreciación de dicho proceso pero también con la exigencia de poner en vigor ciertas normas de desarrollo histórico que lo dirijan por una senda más equilibrada y justa.
\end{abstract}

Palabras clave: humanismo secular, ética protestante, normas supraarbitrarias, globalización, orden nómico

Se ha dicho que la crítica del neoliberalismo requiere la "recuperación de la utopía". La utopía siempre ha fungido como una especie de representación imaginativa de una realidad o situación social posible que, además de alentar la acción política hacia la realización de la misma, sirve como marco comparativo con respecto al cual se contrasta la realidad efectivamente existente. La utopía es la expresión de una dirección determinada. Ante una situación que se considera como indeseable, la utopía aparece como la imagen de lo que sería la situación deseable. Así, la utopía viene siendo en la práctica la expresión de un ideal que asume un carácter normativo para la acción.

Quiero empezar este trabajo mostrando que la utopía es inviable e innecesaria para la crítica de la realidad social. La razón principal por la que es inviable es que la utopía encierra una antinomia fundamental e irresoluble entre dos polos dialécticamente opuestos pero indisolublemente unidos: el ideal (humanista secular) de la libertad y el ideal del control, los cuales constituyen la estructura del motivo religioso humanista secular. En segundo lugar, es la misma utopía la que dirige tanto al liberalismo económico (del cual el neoliberalismo es una expresión contemporánea), como a su aparentemente "acérrimo" enemigo, el estatismo. Esto no es accidental, sino el resultado del énfasis que el primero pone en la "libertad económica" para realizar el ideal de la libertad, frente al énfasis que el segundo pone 
en el control para alcanzar ese mismo ideal. Así —como deberá quedar claro en la primera sección-, la polémica entre estatismo y liberalismo es un pleito entre dos sectas de la misma comunidad de fe.

Una vez desechada la utopía como punto de referencia direccional, surge la pregunta de dónde habrá de encontrarse dicho punto. La segunda sección introduce la distinción entre estructura y dirección para argumentar que la dirección debe encontrarse en la estructura del mundo, la cual está constituida en parte por leyes y normas supraarbitrarias. Las leyes y normas supraarbitrarias (como su nombre lo indica) no son el resultado de ningún fiat normativo humano, sino que más bien "están alli", gobernando y dirigiendo los procesos naturales pero también señalando los límites a la acción humana. La interpretación de estas normas es lo que da lugar a sistemas jurídicos más o menos codificados, pero no se agotan en ellos, sino que constituyen el criterio que permite juzgar y modificar estos sistemas.

Desde este ventajoso punto de vista, la tercera sección reintroduce la clásica polémica de la Methodenstreit para argumentar que no hay en realidad conflicto entre el método de la idealización y el aislamiento en economía, por un lado, y el de la reconstrucción de los procesos económicos concretos, por el otro. Sólo que (contrariamente a la concepción weberiana) la base del análisis no se debe encontrar en los tipos ideales, sino en las leyes tipo (o idionomías) supraarbitrarias. Termino haciendo una crítica del neoliberalismo, en la cuarta y última sección, desde la perspectiva desarrollada en la sección anterior. La alternativa al neoliberalismo que de ella resulta es un retorno a una "ética protestante generalizada" que recupera el "espíritu original" del "capitalismo", el cual no es la acumulación, sino la austeridad y la racionalidad tanto en la adopción de los fines sociales como en el uso de los recursos.

\section{Inviabilidad de la utopía}

El humanismo secular es, fundamentalmente, la expresión de un motivo religioso básico que hizo su aparición en Europa hacia finales de la Edad Media. Un motivo religioso básico es una creencia básica, una convicción que se apodera de una persona y, una vez que se halla profundamente arraigada en el núcleo de la misma persona, tiende a anular las demás creencias que entren en conflicto con la misma y se convierte en el principio organizador de su estructura noética. La creencia básica que define al humanismo secular es que la realización de la naturaleza humana requiere la absoluta autonomía para la personalidad humana, la cual consiste en una supuesta capacidad del ser humano para "legislar sus propias máximas morales" e implica afirmar la autoridad de la razón frente a las autoridades eclesiásticas, la tradición, los libros considerados sagrados y toda autoridad "externa". Esto es lo que se llama "el motivo libertad". Una creencia básica 
como ésta es caracterizada como religiosa porque involucra una toma de posición que limita el espectro de lo que puede ser considerado divino (en el sentido griego), ${ }^{1}$ esto es autosubsistente, excluyendo ciertas posibilidades y permitiendo otras. Para el humanismo secular, particularmente,

la idea de un Dios personal sólo podría ser aceptada en tanto que la personalidad autónoma tuviera necesidad de ella. Esta idea podría ser aceptada como fundamento metafísico para la verdad del pensamiento matemático (Descartes), como un postulado de la razón práctica (Kant), o como un requerimiento del sentimiento religioso (Rousseau). Podría ser aceptada en cualquier otra forma humanista, pero nunca se podría admitir que fuera el fruto de la autorrevelación de un Dios soberano. ${ }^{2}$

Cualquier motivo religioso que postule como absoluto un ente, propiedad o relación inmanente al universo implica un motivo religioso que le es opuesto y antinómico. Junto con él constituye así un sistema de polos que conforman un motivo religioso dialéctico. El motivo religioso humanista es dialéctico porque su motivo religioso básico —el motivo libertad- produce el motivo del dominio de la naturaleza, por lo que se le conoce también como el motivo naturaleza/libertad. Pues el motivo básico libertad, al requerir el control de la naturaleza, "desde sus propias profundidades llama al motivo del dominio de la naturaleza, y conduce así a una religión de la ciencia autónoma objetiva en la que no hay lugar para la personalidad libre". 3

Es en el marco de este motivo religioso básico donde debe entenderse la disputa entre estatismo y liberalismo, así como la utopía que éstos presuponen de manera compartida. Esto se ve claramente en la crítica que Marx hace del liberalismo a través de su teoría del valor. La teoría del valor de Marx no es economía política, si por 'economía política' entendemos una teoría que pretenda aportar elementos para hacer que funcione bien el modo de producción capitalista. Más bien, la teoría del valor pretende aportar los fundamentos que explican por qué hay algo en principio fallido en ese modo de producción: esto es lo que quiere dar a entender Marx cuando dice que su teoría es una crítica de la economía política. Se podría pensar

${ }^{1}$ Para una profunda discusión del concepto griego de lo divino (to theion), véase Werner Jaeger, La teología de los primeros filósofos griegos, principalmente el capítulo I.

${ }^{2}$ Herman Dooyeweerd, A New Critique of Theoretical Thought, vol. I, p. 191. Las traducciones de esta obra aquí incluidas son mías.

${ }^{3}$ Ibid., p. 190. En esta conexión es interesante ver el optimismo de Condorcet, quien declarara "que la naturaleza no ha fijado límite alguno al perfeccionamiento de las facultades humanas, que la perfectibilidad del hombre es realmente indefinida. El progreso de esta perfectibilidad no tiene otro límite que la duración del planeta donde la naturaleza nos ha puesto" (Marie Jean Antoine Nicolas, marqués de Condorcet, Esquisse d'un tableau historique desprogrès de l'esprit humain, p. 3. Citado por J. Habermas, Teoría de la acción comunicativa, I, p. 201). 
que el rechazo radical del sistema capitalista por parte de Marx se halla en la desigualdad social que este sistema genera; pero ésa es una visión muy superficial de su pensamiento. Para Marx, una sociedad burguesa con una buena distribución de la riqueza seguiría siendo indeseable, pues el problema de la sociedad capitalista para Marx es más fundamental que el de la mera distribución de la riqueza. El problema es que las relaciones capitalistas de producción, según Marx, constituyen un freno a ese desarrollo de las fuerzas productivas humanas que es necesario para la superación del reino de la necesidad y el logro de la utopía, es decir, del ideal humanista secular de la personalidad autónoma y libre.

El proyecto de Marx no es resolver el problema de la pobreza dentro del sistema capitalista, sino transformar radicalmente ese sistema desde una perspectiva filosófica determinada. A Marx le interesa criticar la economía política porque para él "la justicia social tiene que ver con la totalidad de las relaciones humanas y cómo estas relaciones impiden o impulsan el desarrollo de la racionalidad, la autoconciencia y la libertad". ${ }^{4}$ Marx soñaba con un reino de prosperidad y abundancia, donde la humanidad estuviera liberada de la necesidad (y por lo tanto del problema de la distribución de la riqueza) y en el cual, ya no estando "gobernada por leyes trascendentales físicas, religiosas, ontológicas, o económicas, los hombres y las mujeres serían libres de crear sus propias formas de arreglos sociales, junto con sus propias historias". ${ }^{5}$ Ésta es la verdadera utopía que dio dirección al pensamiento crítico de Marx. Marx encontró el concepto de libertad que habría de guiarlo en todo su pensamiento posterior en la filosofía de Epicuro (precursor del humanismo secular); pero, como señaló O’Rourke en su importante estudio sobre el concepto marxista de la libertad:

Lo que es más importante para Marx es que Epicuro subordina su filosofía natural a una concepción moral del hombre. Señala que la meta real de la filosofía natural epicúrea no es el establecimiento del conocimiento científico, sino "la ataraxia de la autoconciencia". Cualquier cosa que pudiera perturbar el desarrollo autónomo, autocontenido del espíritu humano hacia este ideal debe ser rechazada, incluyendo tanto las leyes físicas como los así llamados cuerpos celestes divinos. De hecho, la autonomía del hombre es concebida de una manera tan radical que no puede haber "nada bueno que se encuentre fuera de él; el único bien que tiene en relación con el mundo es el movimiento negativo, ser libre de él". ${ }^{6}$

Esta ataraxia es la meta ética final de la Revolución y de la liquidación del sistema capitalista de producción. Como se puede ver, el proyecto de

${ }^{4}$ George E. McCarthy, Marx and the Ancients, p. 264.

${ }^{5}$ Ibid.

${ }^{6}$ James O'Rourke, The Problem of Freedom in Marxist Thought: An Analysis of the Treatment of Human Freedom by Marx, Engels, Lenin, and Contemporary Soviet Philosophy, p. 14. 
Marx no es otra cosa que la realización plena del ideal religioso humanista secular de la libertad, con su típico desconocimiento y rechazo de leyes "externas" supraarbitrarias.

¿Es viable la utopía que presupone el pensamiento crítico de Marx? Sostengo que no. La antinomia religiosa fundamental del humanismo secular hace imposible lograr, simultáneamente, el control absoluto de la naturaleza (el cual además requiere que no haya externalidades ni limitaciones en los recursos naturales) y la absoluta autonomía de la voluntad, pues el primero presupone que la naturaleza (y la sociedad) están regidas por leyes "trascendentales" (esto es, supraarbitrarias) cuyo conocimiento y actuar conforme a ellas hace posible el control (es decir, no son el resultado de la actividad "legisladora" de la voluntad autónoma); mientras que la segunda requiere que no haya tales leyes, sino que los humanos "superen el reino de la necesidad" y sean libres de crear los arreglos sociales de manera enteramente autónoma (es decir, legislando autónoma y libremente las nuevas formas y arreglos, y desechando cualquier forma o arreglo que no sea autónomamente generado). Constituye un aserción analítica la afirmación de que no se puede arrasar con las leyes y normas que gobiernan el cosmos natural y la vida humana (es decir, ignorarlas como si no existieran) al mismo tiempo que se hace uso de las mismas para dominar la naturaleza y moldear la sociedad conforme a los dictados arbitrarios del hombre (lo cual supone que dichas leyes y normas efectivamente operan y no operan realmente).

Pero es precisamente la existencia de externalidades y limitaciones lo que da testimonio de que la naturaleza y la sociedad están sujetas a leyes supraarbitrarias que hacen imposible "la superación de la necesidad". Creo que éste es el punto crucial de quiebre, de toma de posición direccional que tiene que admitir un nuevo discurso abocado a la crítica del neoliberalismo. Pero esa crítica también habrá de tocar al estatismo, pues uno y otro - a pesar de apariencias en contrario- no son sino caras de la misma moneda; son expresiones de los polos dialécticos, indisolublemente unidos, del mismo motivo religioso.

\section{Estructura y dirección}

Contra la visión humanista secular de una humanidad capaz de proveerse de sus propias normas y leyes ad placitum, de superar el "reino de la necesidad", se erige la infranqueable barrera de la Ley. La Ley es la estructura del cosmos, la constitución originaria de cada cosa, lo que hace ser a cada entidad lo que es. La respuesta de los seres humanos a la Ley es la dirección por virtud de la cual las mismas cosas son ordenadas de manera obediente o desobediente a la Ley. Por ejemplo, la idionomía o ley tipo de la familia es la norma constante de la familia, la norma por virtud de la cual es posible 
reconocer familias en diferentes épocas históricas y juzgar las mismas como "normales" (conforme a la norma) o no. Sin embargo, una familia puede estar mal dirigida, de modo que aunque sea efectivamente una familia y reconocible como tal, no deja de resultar un tanto anómala. Por ejemplo, quebrantar la norma de fidelidad conyugal genera muchas situaciones de sufrimiento o desajuste conyugal que no siempre culminan en la destrucción de la familia. Aquí la falta de respeto a la ley tipo no necesariamente provoca la destrucción de la estructura matrimonial concreta, pero sí una dirección fallida de la misma. Así, la dirección puede ser una distorsión de la ley tipo — si es desobediente a la norma - o bien un cumplimiento de la misma. Sostengo que sin esta distinción es imposible juzgar cualquier institución o fenómeno social como la globalización, la tendencia a la privatización, o los problemas sociales que plantean los mercados actuales.

Es importante en este punto subrayar la diferencia que hay entre el orden nómico del mundo, por un lado, y la estructura fáctica que tienen las cosas reales concretas. Por ejemplo, una determinada familia puede estar organizada de una manera distorsionada y reflejar así la idionomía de la familia de una manera indirecta u opaca. Esta organización peculiar de esta familia concreta es la estructura concreta de la misma, la cual no debe ser confundida con la ley tipo correspondiente.

A pesar de ser meridianamente clara, esta distinción entre estructura y dirección ha sido continuamente confundida o ignorada en la historia de la cultura occidental. Una de las confusiones más típicas, desde luego, es la que da lugar al monaquismo. Dentro de la tradición cristiana occidental, el monaquismo es una fuga mística del mundo, basada precisamente en una confusión de los dos sentidos de la palabra 'mundo' que aparecen en las Escrituras. Conforme al primer sentido, 'mundo' significa precisamente el cosmos, la Ley y las cosas existentes en él; conforme al segundo, 'mundo' significa la dirección que las personas, comunidades o estructuras sociales concretas han adoptado. ${ }^{7} \mathrm{El}$ monaquismo medieval (al igual que el anabaptismo, el cual es una expresión extrema del monaquismo), abrumado por la maldad imperante y de antemano derrotado ante la misma, pensó que la maldad era intrínseca al mundo, que era parte de su estructura nómica (debida a la Caída), y no podía concebir que fuera posible reformar o restaurar las instituciones concretas conforme a su norma originaria. La cosmovisión revolucionaria de inspiración humanista secular, en cambio, pretende destruir de raíz dichas estructuras concretas, para crear un "nuevo hombre" libre de la Ley. Así, mientras los monjes huyen de las estructuras concretas,

${ }^{7}$ Un texto típico del primer sentido es, por ejemplo, "el mundo por [el Verbo] fue hecho" (Jn 1:10); uno del segundo es "[los discípulos] no son del mundo, como tampoco yo soy del mundo" (Jn 17:14). Al decir que sus discípulos no son del mundo, Jesús estaba diciendo que ya no siguen la dirección apóstata y desobediente de la Ley, sino que ahora han sido regenerados para que entren en un pacto de obediencia a la misma. 
al considerarlas perversas e irredimibles, los revolucionarios ignoran la Ley para buscar en la Utopía (= el lugar inexistente) una forma de construir el mundo que pretende desconocer el orden nómico.

Contra estas concepciones es menester tomarse en serio la idea de que el mundo está sujeto a leyes y normas supraarbitrarias y que los males que lo aquejan no pueden ser conceptualizados sino como transgresiones a dichas leyes. Creo que ésta es la única manera apropiada de replantearse un discurso crítico del neoliberalismo y la globalización que no tienda a satanizar este proceso.

Por lo tanto, la filosofía social apropiada para estos menesteres debe estar fundamentada en una ontología que concibe el cosmos como una integridad definida en sus trazos generales por tres distinciones fundamentales, a saber:

1) la distinción entre ley y sujeto;

2) la distinción de varios aspectos modales;

3) la distinción entre tipicalidad y modalidad.

Procederé a discutir cada una de estas distinciones por separado.

\section{1. La distinción entre ley y sujeto}

Es necesario distinguir en el cosmos dos lados constitutivos mutuamente irreducibles e imprescindibles: el lado ley y el lado sujeto. En el mundo no solamente encontramos cosas, procesos, eventos y agregados concretos, sino también que los mismos están sujetos a leyes. De hecho, la investigación científica tiene que presuponer que los tales están sujetos a leyes, pues una de sus metas es determinar precisamente cuáles son éstas. Si no hubiera leyes que determinar, sería imposible encontrar regularidades y explicaciones de los fenómenos empíricos, y la investigación científica carecería de sentido.

El hecho de que no haya una teoría del campo unificado en física, así como la existencia de diversas interpretaciones de la física, ha dado pie a los historicistas para introducir una forma de relativismo incluso en el nivel de las ciencias naturales. Según este relativismo, no hay leyes a las que los fenómenos estén sujetos, sino que estos mismos fenómenos están constituidos por esquemas conceptuales diversos que dan lugar a diferentes "mundos". Dejando de lado las incoherencias de esta extraña doctrina, ${ }^{8}$ está claro que incluso la experiencia preteórica tiene un sentido bastante agudo del hecho de que no todo va. Para lograr objetivos prácticos tenemos

\footnotetext{
${ }^{8}$ Ya enseñada por Epicuro y sostenida por Karl Marx, como vimos antes. Para una crítica del historicismo, véase Roy A. Clouser, "A Critique of Historicism"; Adolfo García de la Sienra, "La dialéctica del realismo interno"; y Guillermo Hurtado, "La incoherencia del realismo interno".
} 
que seguir ciertas directrices y obedecer ciertas leyes, aun cuando nadie tenga la teoría general de las mismas: la técnica y la tecnología están basadas en este hecho.

Pero la constatación de este hecho no debe conducirnos a una forma de imperialismo naturalista en las ciencias sociales. A diferencia de las leyes naturales -aritméticas, espaciales, cinemáticas, físicas, bióticas y psicológicas-, las cuales no es posible desobedecer, las leyes que rigen otros aspectos de la vida humana son de carácter normativo y pueden ser desobedecidas. La ley de la gravedad, por virtud de la cual los cuerpos tienden hacia los centros de masa de los cuerpos más masivos, no puede ser desobedecida pues los cuerpos están continuamente sujetos a la misma, sin que en ello medie la voluntad o la conciencia. La conciencia de la ley de gravedad puede conducir a reglas prácticas positivas, como "no saltar al vacío desde una altura grande", pero estas máximas prácticas presuponen que las leyes naturales siempre operan. Las normas de otros aspectos operan también siempre, pero los efectos de transgredirlas generalmente son sociales y tardan en manifestarse. Por ejemplo, el trato grosero en una organización puede provocar resentimientos que dificulten la interacción y terminen por disolver aquélla; regalar calificaciones en una institución académica causa la pérdida de reputación de la misma; el no aplicar la ley por parte del gobierno de un Estado puede hacer que crezca la delincuencia y que se ponga en riesgo su viabilidad institucional. La tesis central que defiendo en este escrito es que los males sociales que vemos son el efecto de la violación de las normas supraarbitrarias: las sociedades humanas actuales están cosechando el fruto de la semilla que sembraron.

El correlato de la ley es aquello que está sujetado a la ley. Los entes, los procesos, los eventos individuales concretos, incluyendo a los humanos así como las organizaciones sociales, están todos sujetos a leyes y normas. Es característico del ser concreto el estar por debajo de la ley y tener que desenvolverse conforme a condiciones para poder mantenerse en la existencia. Este carácter de sujeción se expresa en el hecho de que los entes pertenecen a conjuntos y clases: si bien hay conjuntos arbitrariamente construidos, toda ley define un conjunto, a saber, el conjunto de los entes que satisfacen o cumplen dicha ley.

\subsection{La distinción de varios aspectos modales}

La experiencia científica y la reflexión filosófica han puesto de manifiesto que el lado ley del cosmos está constituido por una multitud de niveles, estratos o modalidades de leyes que son irreducibles entre sí. Así, es posible distinguir varias modalidades, a saber, las "naturales" (la numérica, la espacial, la cinemática, la física, la biótica y la psíquica) así como las normativas (la analítica, la cultural, la lingual, la social, la económica, la 
estética, la diquética, ${ }^{9}$ la ética y la fídica). Las leyes modales definen reinos, pero eso no quiere decir que necesariamente sujeten sólo a los entes pertenecientes a un reino. Por ejemplo, los habitantes del reino de las plantas están sujetos no sólo a las leyes bióticas modales, sino también a las físicas. Los animales están sujetos no sólo a las psíquicas, sino también a las anteriormente mencionadas. El hombre es el único ser sujeto a todas las leyes; pero en general las cosas concretas con las que nos topamos en el diario vivir están sujetas a más de una modalidad de leyes. "Las esferas de leyes modales están constituidas por relaciones generales, no específicas, entre cosas o eventos [además de procesos y agregados] independientemente de su carácter."10

Ninguna de estas modalidades es más fundamental que las demás en un sentido ontológico, pues son interdependientes. Esto no quiere decir, por ejemplo, que no pueda existir ningún ente en el reino mineral sin que exista un ser con mente (funcionando en el aspecto psíquico) que sea consciente de aquél. Lo que quiere decir es que el núcleo de una modalidad remite a otras modalidades ya sea anticipándolas o reflejando las anteriores. En efecto, las modalidades están ordenadas de un modo lineal, el cual se observa en que propiedades de modalidades anteriores pueden tener ejemplificaciones que no tienen propiedades de las posteriores y, más aún, en que los miembros de un reino posterior siempre están sujetados a las leyes de un reino anterior.

\subsection{Tipicalidad y modalidad}

Los entes, procesos, eventos y agregados individuales concretos están sujetos a multitud de leyes. Los llamados reinos de entes están definidos precisamente por la "más alta" modalidad de leyes a la que están sujetos. Por ejemplo, las piedras están sujetas a leyes físicas, pero no a leyes bióticas. Las plantas están sujetas también a leyes físicas, pero además lo están a las bióticas. Los animales están sujetos a las anteriores, pero también a leyes psíquicas. El hombre, en cambio, está sujeto a todas las leyes naturales, pero, además, también está sujeto a normas. Los entes individuales no humanos tienen una idionomía típica que los ubica en una clase natural; por ejemplo, el átomo de helio, el pino o la ballena azul. Las leyes que definen esta idionomía típica —o la clase de los entes que la poseen- son llamadas leyes típicas. Las leyes modales, en cambio, valen para todo un reino de entes, y en este sentido decimos que tienen validez "universal".

La idionomía de una clase natural es un racimo de leyes que determina "qué propiedades y qué propensiones tiene un sujeto [ente, proceso,

${ }^{9}$ Del griego diké, que significa justicia. ‘Diquético' significa relativo a la justicia.

${ }^{10}$ Marinus D. Stafleu, "The Idionomy of Natural Kinds and the Biological Concept of a Species", p. 155. 
evento, agregado], cómo se relaciona con su entorno, en qué circunstancia existe, cómo llega a ser, a cambiar y a perecer". ${ }^{11}$ Por ejemplo, la idionomía de una especie de mariposa establece en qué condiciones se gesta una nueva oruga, en qué condiciones puede vivir y desarrollarse normalmente, cuáles son los pasos de la secuencia del desarrollo normal, de qué manera se puede relacionar con el entorno para alimentarse (o servir de alimento), cómo se transforma en mariposa, su duración, las condiciones que la hacen perecer, etcétera. La idionomía de la mariposa determina todo el conjunto de posibilidades objetivas de la mariposa, las cuales pueden realizarse o no, dependiendo de las condiciones en que quede puesta.

Este concepto de idionomía nos permitirá abordar desde una nueva luz la vieja pero crucial (para la filosofía social) polémica de la Methodenstreit.

\section{La Methodenstreit revisada}

La cuestión de la ausencia o la presencia del sujeto social concreto en las construcciones del conocimiento económico sólo se puede plantear dentro de la discusión relativa a si la economía debe ser una disciplina abstracta y matemática, construida más conforme al modelo de las ciencias naturales, o una disciplina "concreta" e "histórica" que responda a las demandas ontológicas y epistemológicas relevantes. Pero esta discusión no es nueva, pues se planteó con gran profundidad en el contexto de la Methodenstreit (Batalla de los Métodos), aquella famosa polémica que tuvo lugar en Alemania a fines del siglo XIX.

Si por "sujeto social concreto" entendemos algo así como "la sociedad en su concreción" o "los individuos concretos en sus relaciones concretas", entonces en la teoría económica abstracta es muy mediada e indirecta la referencia al sujeto social concreto, pues se da usualmente a través del concepto de homo œconomicus o de "agente", donde el agente es caracterizado mediante una función de utilidad que posee características matemáticamente "agradables" (continuidad, diferenciabilidad, etcétera). Este concepto de agente no permite imaginar algo así como un sujeto social concreto, sino, en todo caso, varios sujetos (un agente puede representar a una persona individual, un hogar o una institución). De hecho, el concepto de sujeto social sugiere algo así como una persona o grupo social con un grado de cohesión tal que puede ser considerado como una sola conciencia o voluntad. Pero esto nos conduce a otro problema, que es el de la disputa entre individualismo y colectivismo, el cual habré de abordar adelante.

A mi modo de ver, la cuestión de una teoría económica en la que el o los sujetos (personas y grupos humanos) son considerados en su concreción nos remite a la vieja polémica de si la economía debe ser una Naturwissen-

${ }^{11}$ Ibid. 
schaft o una Gesellschaftswissenschaft. Como lo ha argumentado Mirows$\mathrm{ki}^{12}$ buena parte de la teoría económica actual — particularmente la que está basada en la obra de Pareto y Edgeworth - está construida siguiendo el modelo de la física matemática y por lo tanto está conscientemente construida como una Naturwissenschaft. Sin embargo, ya Gustav von Schmoller insistió en que la Gesellschaftswissenschaft era una ciencia unitaria que "debiera estudiar las relaciones no sólo entre el hombre y los bienes materiales, sino entre el hombre y sus congéneres [...]. El orden económico ha de ser considerado sólo como un aspecto y parte integral de la vida social entera y como tal ha de ser evaluado desde un punto de vista ético."13

Lo que está proponiendo Schmoller, desde luego, es una especie de ciencia total de la sociedad, criticando implícitamente la viabilidad o incluso la posibilidad de una economía como ciencia especial. La tesis que yo defiendo es que las dos son necesarias: la filosofía social debe proveer el enfoque fundamental, dentro del cual ha de construirse e interpretarse la economía como ciencia especial, y, además, la economía debe reflejar (anticipar o retrocipar) las otras esferas nómicas en su propia estructura conceptual interna. Esto se puede hacer a través de lo que he llamado una función normativa, ${ }^{14}$ la cual refleja normas de diferentes modalidades. A grandes rasgos, una función normativa sustituiría a la típica función de bienestar social, con lo que el "análisis del bienestar" tendría que ser sustituido con un "análisis ético", es decir, un análisis del cumplimiento de las normas sociales. No es aventurado anticipar que los óptimos de Pareto de las usuales funciones de utilidad se hallarán muy lejos de los óptimos de estas funciones normativas.

El concepto de función normativa permite combinar el enfoque "concreto" con el abstracto. El enfoque abstracto se caracteriza por aislar algunos aspectos de la vida social para ver qué efectos tienen ciertas tendencias si se las dejase operar libremente. Como ha argumentado Uskali Mäki, el método del aislamiento [isolation] o idealización permite captar la esencia del fenómeno sin interferencias externas. ${ }^{15}$ La función normativa permite caracterizar la idea de sistemas de necesidades "éticamente" (i.e., nómicamente) óptimos, haciendo abstracción del sujeto social y las relaciones de poder. En cualquier caso, la interpretación de la teoría abstracta (el "desaislamiento", para usar la terminología de Mäki) requiere una filosofía social "concreta".

El problema del "sujeto social" aparece nuevamente en conexión con las funciones normativas. La agenda liberal siempre ha requerido que las

\footnotetext{
12 Philip Mirowski, More Heat than Light.

${ }^{13}$ Citado por George G. Iggers (comp.), The German Conception of History, pp. 131 y ss.

${ }^{14}$ En Adolfo García de la Sienra, "Reformational Economic Theory".

${ }^{15}$ Véase, por ejemplo, Uskali Mäki, "On the Method of Isolation in Economics" y "The Market as an Isolated Causal Process: A Metaphysical Ground for Realism”.
} 
funciones que hayan de ser utilizadas para evaluar los efectos sociales de las políticas públicas o de los mercados sean el resultado de una especie de agregación de "preferencias" individuales sobre "estados sociales" posibles. El Teorema de Imposibilidad de Arrow, al mostrar que tal agregación es lógicamente imposible, ha replanteado nuevamente el problema de la "elección social". ¿Quién ha de determinar o cómo ha de determinarse la función de "bienestar social" que defina cuáles son los estados sociales más "deseables"? La conclusión de Arrow es que no es posible hacer esa determinación de manera democrática, a menos que exista un consenso social previo con respecto a los "fines" de la sociedad. ${ }^{16}$ Ésta es la manera en que la Ley impone su eficacia en el terreno de la teoría de la elección social: estos fines no son otros que los estipulados en las idionomías de las formas sociales. Las funciones normativas son implícitamente determinadas por sujetos sociales conscientes y responsables — comunidades- que asumen como propias estas funciones normativas, convencidos de que las mismas reflejan el orden nómico que rige la vida social.

En cualquier caso, la elaboración teórica y sistemática de las funciones normativas requiere la filosofía social; pero, además, la filosofía social es necesaria para entender la globalización, pues no es posible entender el complejo fenómeno de la globalización desde el punto de visto exclusivo de la economía abstracta.

Esto ha llevado a plantear el problema de si es posible usar nuevos conceptos procedentes de otras disciplinas de las ciencias sociales para el entendimiento de la globalización. La inquietud es legítima pero está mal planteada, porque no es posible importar conceptos de otras ciencias sociales sin una filosofía social que los coordine, so pena de correr el riesgo de caer en la diletancia. La cuestión fundamental no es si es posible importar conceptos de otras disciplinas, sino si es posible prescindir de una filosofía social en el análisis de los fenómenos sociales. Ya desde principios del siglo XIX, con la introducción de la sociología como una "ciencia independiente", algunos pensaron que era posible una ciencia afilosófica de la realidad social. Por lo tanto, el problema fundamental que hay que tratar antes que nada es el de si la sociología así entendida es la que debe proporcionar ese enfoque total de la sociedad.

Herman Dooyeweerd planteó el problema con gran claridad:

Pero si todo aspecto modal posible de la sociedad humana pertenece ya al campo de indagación de una ciencia especial, ¿cómo puede quedar algún lugar para la sociología como una ciencia especial? ¿Acaso las ciencias de la geografía social, la psicología y la historia social, la filología y la lingüística, la economía social y la jurisprudencia, la ética social, la antropología de la

${ }^{16}$ Kenneth J. Arrow, Social Choice and Individual Values, p. 88. Discuto este tópico con cierto detalle en "A New Agenda for Economic Theory". 
religión y otras no han ya subsumido todo el campo de investigación sobre las relaciones humanas sociales? ¿Puede la aún inmadura ciencia de la sociología, por lo tanto, ser algo más que un resumen diletante de lo que todas las ciencias sociales especiales (cada una en su territorio) nos han enseñado a través de su sofisticada investigación de nuestra sociedad humana? ${ }^{17}$

Si la sociología es concebida como una ciencia especial (y ésta es una concepción que se enfrenta a serias dificultades), entonces sigue abierta la cuestión de una visión total de la sociedad. Pero la concepción de la sociología como una teoría de la totalidad de la sociedad humana se enfrenta a los siguientes problemas.

1) Una teoría de la totalidad social está forzada a considerar las relaciones mutuas y la coherencia de las diferentes modalidades o esferas sociales, lo cual no se puede hacer sin presuponer alguna concepción filosófica. Pero entonces la sociología no puede meramente seguir los métodos de investigación de las ciencias especiales, pues más bien debe establecer los fundamentos de estas ciencias. Esto echa por tierra la pretensión de la sociología de ser una ciencia "empírica", independiente de la filosofía, que trata con la totalidad de la vida social.

2) La sociología no resuelve el problema filosófico básico de una teoría de la totalidad social, el cual es el relativo a la naturaleza de las estructuras de totalidad típicas de las relaciones sociales en toda su diversidad modal. Todo tipo de estructura social funciona simultáneamente en todas las modalidades, por lo que la representación teórica de su idionomía debe tener en cuenta este hecho.

3) Otro problema de la sociología es su pretendido enfoque "libre de valores" y "apegado a los hechos". El problema es que no es posible entender los hechos sociales sin referencia a valores, suponiendo por lo tanto que los tales sean efectivamente valores. Tampoco es posible proveer explicaciones causales sin suponer estos valores.

Por lo tanto, la Gesellschaftswissenschaft tiene que ser necesariamente una filosofía social. A partir de la filosofía que he esbozado se debe analizar el proceso de globalización y someter a crítica el "neoliberalismo", pero es necesario introducir otras categorías y distinciones antes de emprender esta tarea.

La primera distinción que es necesario introducir es la que hay entre las comunidades diferenciadas y las indiferenciadas. Las comunidades indiferenciadas se caracterizan por un lazo comunal (por ejemplo: lazos consanguíneos o un juramento de lealtad) dentro del cual se realizan los más

${ }^{17}$ Herman Dooyeweerd, A Christian Theory of Social Institutions, p. 32. 
diversos principios estructurales (económico, diquético, fídico, etcétera), los cuales quedan peculiarmente entrelazados por ese nexo. Un ejemplo de comunidad indiferenciada organizada sobre el principio de la familia es el clan o la familia patriarcal. En un clan, el lazo sanguíneo prevalece y ordena todas las actividades sociales, las cuales por lo mismo no están claramente diferenciadas. Así, diferentes funciones recaen sobre la misma figura humana y en cualquier caso no existen órganos especiales específicos para cumplir las diferentes funciones (económica, jurídica, cúltica), así como tampoco aparece la figura del individuo; esto es, los miembros de la comunidad no conocen la idea de intereses personales al margen del metabolismo de la comunidad. Para el gremio medieval y la comunidad indígena mexicana actual (o las hermandades que describe Manuel Payno), por ejemplo, la descripción sigue siendo válida, si bien allí el principio organizador no es de carácter familiar, sino político o étnico.

El proceso histórico de diferenciación, el cual siempre va a la par con el proceso de individuación, tiene el efecto de disolver las comunidades indiferenciadas y de generar tanto instituciones organizadas diferenciadas como la figura del interés personal de los miembros de las mismas. Así, aparecen por un lado relaciones comunales (institucionales) diferenciadas (aparte del matrimonio o la familia nuclear, las cuales son de carácter natural) y por otro relaciones interindividuales de un carácter no comunal. Tanto unas como las otras tienen una idionomía que regula sus diferentes formas concretas positivas.

El proceso de diferenciación viene siendo el análogo social de la aparición de diversos especímenes conforme a su idionomía en el proceso evolutivo natural. Así como la vida se puede manifestar en organismos con una estructura indiferenciada y dar lugar a estructuras orgánicas más diferenciadas, la sociedad humana pasa de etapas indiferenciadas a una gran complejidad en cuanto a la multiplicación de sus órganos (lo cual fomenta la división social del trabajo). La diferencia entre la aparición de órganos naturales y sociales es que las idionomías de los segundos sólo pueden asumir una forma concreta positiva a través de la acción formativa humana.

A diferencia del individualismo burgués, que concibe a los miembros de la sociedad como "individuos", como algo anterior y en principio independiente de las comunidades (indiferenciadas o no), esta filosofía social sostiene que los "individuos" no pueden existir al margen de toda comunidad, sino que el ser humano es completamente dependiente de las instituciones para su existencia. El caso de Robinson Crusoe no es un contraejemplo a esta tesis, sino al contrario: las habilidades que le permiten sobrevivir en la isla desierta sólo pudo haberlas adquirido en sociedad, y no sólo eso: incluso no pudo haber sobrevivido durante sus primeros años sin otros humanos o animales que le dieran sustento y cuidado. Esta filosofía social rechaza, por lo tanto, la fantasía del "contrato social": la figura del contrato 
no explica ni la génesis ni la preservación de los lazos intercomunales, sino tan sólo el de las asociaciones libres, esto es, las generadas a partir de la voluntad de concretar relaciones interindividuales. Las primeras siempre se basan en una relación de autoridad y subordinación; las segundas no. Las primeras no se pueden romper con facilidad y en principio son para toda la vida; las segundas se rompen con más facilidad (desde todos los puntos de vista, es más difícil divorciarse que abandonar el club de golf o la asociación filantrópica; o cambiar de nacionalidad que cambiar de peña futbolística).

En oposición a la concepción individualista burguesa (pero siempre dentro del mismo motivo religioso del humanismo secular), el colectivismo en sus diversas formas (nacionalsocialistas, socialistas y comunistas) tiende no sólo a negar la supuesta independencia del "individuo" frente a la "sociedad", sino incluso a elevar una de sus esferas diferenciadas al rango de "totalidad" (generalmente el Estado), para luego tratar de revertir los procesos de diferenciación e individuación atribuyéndoles el carácter de "perversiones burguesas". Esto tiende a anular el ámbito de intereses particulares de la persona así como la función propia de las otras esferas sociales, al constituir un intento por someterlas todas a la función guía propia de la esfera que se ha postulado como "totalidad social".

La idea de que las diferentes esferas son soberanas ha sido expresada como relativa a la imposibilidad de reducir las propiedades y leyes de una modalidad a otra(s). El materialismo reductivo ${ }^{18}$ sostiene que las esferas son soberanas, pero que las modalidades "más altas" (las que se erigen sobre la física, como la biótica, y luego las que se erigen sobre éstas) no pueden existir sin las "más bajas", pero las más bajas sí pueden existir sin las más altas. El argumento que utiliza el materialismo reductivo para establecer esto está basado en la teoría de la evolución, la cual implica que pueden existir sujetos cualificados por leyes de la modalidad física sin que existan sujetos cualificados por la biótica o la psíquica, pero no viceversa:

La teoría de la evolución y la cosmología implican una estructura de niveles que tiene aproximadamente la siguiente forma (empezando con el nivel más bajo): partículas elementales, núcleos atómicos, moléculas, cuerpos, organismos pasivos, organismos activos, organismos prepsíquicos, organismos con una psyche sensorial, y organismos con una psyche intelectual -la conciencia humana. ${ }^{19}$

Esto es desde luego aceptable, pero no es lo mismo decir que no pueden existir sujetos vivos sin cuerpos físicos que decir que no pueden existir leyes

\footnotetext{
${ }^{18}$ Esta posición está representada por pensadores tan importantes como Samuel Alexander, Nicolai Hartman, Roman Ingarden, Michael Polanyi, Mario Bunge e Igvar Johansson.

${ }^{19}$ Igvar Johansson, Ontological Investigations, p. 23.
} 
bióticas sin leyes físicas, pues las leyes no pueden ser propiedades individuales. La famosa idea de la transformación de los cambios cuantitativos en cualitativos es una forma tosca o inexacta de expresar que hay conformidad a la ley no sólo dentro de los niveles, sino también entre ellos. Esto significa que el surgimiento de seres con propiedades de un nivel más alto está regida por leyes, lo cual sería imposible si tales leyes no tuvieran una eficacia anterior a la aparición de las nuevas entidades. En especial para los niveles sociales, vemos que esas leyes interniveles dirigen un proceso de apertura y diferenciación de la cultura, dando lugar a una vastedad de instituciones y relaciones sociales de diversos tipos. Estas leyes abren la conciencia, el lenguaje y el modo lógico de pensar; pero también el uso de herramientas y la positivación de idionomías a través del libre diseño basado en el conocimiento de las propiedades de las cosas.

Las leyes interniveles son precisamente las idionomías, las cuales establecen, como vimos arriba, qué propiedades y qué propensiones tiene un sujeto (ente, proceso, evento, agregado), cómo se relaciona con su entorno, en qué circunstancia existe, cómo llega a ser, a cambiar y a perecer. El proceso evolutivo es impensable sin la eficacia universal y omnipresente de las idionomías, pues son éstas las que establecen las condiciones bajo las cuales emergen los especímenes de una clase natural, en el proceso evolutivo natural, o las organizaciones y relaciones sociales en el proceso evolutivo mediado por la conciencia humana. Esto significa que los factores integrativos son precisamente las idionomías tanto de las comunidades como de las relaciones sociales interindividuales. Las normas supraarbitrarias contenidas en las idionomías, al ser positivadas en la constitución de una institución o relación interindividual, unifican voluntades (o ponen a los agentes en relaciones de antagonismo) a través del apego a las normas positivas resultantes que le dan una estructura concreta a la misma institución o relación.

Una forma de determinar el contenido de las idionomías sociales consiste en observar las funciones que caracterizan al ser humano: grosso modo, cada una de estas funciones apunta hacia una esfera de vida específica, cuyo mantenimiento y desarrollo requiere que se creen ciertas organizaciones sociales. Estas organizaciones no son arbitrarias sino que están enraizadas en la naturaleza humana y tienen que adecuarse a la finalidad misma que les da una razón de ser, pero es el proceso mismo de adecuarse a esta finalidad lo que devela el contenido de las idionomías, pues éstas son el sistema de normas cuyo seguimiento es necesario para crear y mantener las organizaciones de un tipo. Un criterio que propongo para identificar las idionomías de las comunidades y organizaciones sociales es éste: una vez que la identificación de las funciones humanas (las cuales se observan operando en todas las épocas) ha sido llevada a cabo, es posible formarse una idea del tipo de organizaciones sociales que requiere el desarrollo de 
dichas funciones. A grandes rasgos, la idionomía de cualquiera de ellas se puede inferir a partir de la finalidad que persigue, pero tomando en cuenta que todas las organizaciones sociales tienen que obedecer normas de todas las modalidades, no nada más de la modalidad que determina su finalidad (por ejemplo, la estética en las organizaciones cuya finalidad es el arte). En efecto, a partir de la finalidad de una organización o relación social podemos inferir los deberes que la misma requiere, como John Searle ha sugerido. ${ }^{20}$ Por ejemplo, el ser humano es capaz de producir arte. Pero para su despliegue el arte requiere instituciones que transmitan sus técnicas, que lo exhiban, que lo financien. El entendimiento de la naturaleza del arte y, a partir del mismo, del tipo y funciones de las organizaciones que su desarrollo requiere, nos puede dar una idea bastante clara y rica en contenido de las idionomías de dichas organizaciones. La existencia de esta idea, por lo demás, está presupuesta en la codificación de normas positivas para tales organizaciones. Este procedimiento se puede generalizar a otras esferas. Está claro, por lo dicho, que la identificación de los contenidos de las idionomías se fundamenta en la antropología filosófica.

Ahora bien, la antropología filosófica cristiana debe afirmar además que el hombre no puede ser definido meramente en términos de las funciones que lo caracterizan y que se manifiestan en los órganos sociales, pues además de funcionar en las modalidades correspondientes, de estar sujeto a toda suerte de leyes y normas, el hombre está abierto en principio a la idea de algo que trasciende la inmanencia; que trasciende tanto el lado sujeto como el lado ley del cosmos. La necesidad que tiene el ser humano de postular un Origen, un "algo" autoexistente para construir su pensamiento, lo define como homo religiosus, lo cual implica que siempre está obligado a construir su vida personal y comunitaria sobre la base de un motivo religioso u otro. ${ }^{21} \mathrm{El}$ materialismo reductivo, por ejemplo, tiende a atribuir existencia eterna (divina, en el sentido técnico de la palabra) a la energía física, aunque hay concepciones religiosas variadas dentro del mismo como la de Johansson, quien sostiene que lo que tiene existencia autosubsistente es el espacio entendido de manera no relacional sino absoluta. A diferencia del materialismo reductivo, el teísmo sostiene que el espacio es relacional y que tanto éste como la energía física, los números, y desde luego el cosmos en todos sus lados y aspectos, fueron creados por una divinidad trascendente de la cual dependen existencialmente todos ellos. Así, el teísmo acepta la evolución pero no el evolucionismo, pues al no tener que poner un Grund inmanente al cosmos puede concebir perfectamente que los niveles o modalidades tienen una eficacia previa al proceso evolutivo y que lo condiciona. Pero esta antropología filosófica tiene implicaciones

${ }^{20}$ John R. Searle, "Cómo derivar 'debe' de 'es' ".

${ }^{21}$ Para una definición técnica del concepto de motivo religioso, véase Herman Dooyeweerd, Las raíces de la cultura occidental, capítulo 1. 
políticas e implicaciones importantes para el análisis de la globalización. A tal análisis procedo finalmente.

\section{Crítica del neoliberalismo: ¿reforma o revolución?}

Ante la estrepitosa caída de los regímenes burocráticos socialistas de Europa del Este, los correligionarios humanistas seculares de los comunistas - los liberales - se han apresurado a decretar el Triunfo Final de la Weltanschauung burguesa y sus nuevas formas de organizar la sociedad humana. Este decreto se ha dado en medio de un proceso de integración de mercados (principalmente financieros) a nivel mundial, conocido como "globalización", y de una proclamación del fetiche del "mercado" como mecanismo automático de organización social. Esta proclamación es lo que se conoce como "neoliberalismo". Así, a diferencia de la globalización, que es el modo histórico concreto (si bien distorsionado) en que está avanzando el proceso evolutivo de integración dirigido por las idionomías, el neoliberalismo es una mera ideología que pone los derechos a la propiedad privada, el consumo y la ganancia como los principios absolutos y omnicomprensivos de la vida humana.

El problema principal con el neoliberalismo y su práctica es que tiende a arrasar las estructuras sociales a través de una indebida expansión de una de ellas -el mercado-, pero ni siquiera el mercado en su integridad, sino el mercado de capital financiero. Una de las normas supraarbitrarias que gobiernan el devenir histórico es la norma de economía cultural, la cual demanda que el desarrollo de una sociedad sea "balanceado" en el sentido de que todas las esferas e instituciones deben irse desarrollando simultáneamente. No es factible tener, por ejemplo, una industria muy integrada y dinámica combinada con un Estado débil y carente de autoridad. El "desarrollo" social debe ser simultáneo en todas las áreas de la vida. Que la norma de economía cultural efectivamente rige el desarrollo histórico como una norma supraarbitraria se aprecia en el hecho de que los intentos por desarrollar una esfera de la sociedad a expensas de las demás generalmente conducen al subdesarrollo de las segundas. Esto se puede advertir, por ejemplo, en la destrucción de la economía que tuvo y sigue teniendo lugar en los países socialistas. En general, violar la norma de economía cultural tiene implicaciones totalitarias, y es en las consecuencias y efectos perversos del totalitarismo donde se puede apreciar su efectividad y carácter suprahistórico. ${ }^{22}$

\footnotetext{
${ }^{22}$ Para un análisis de la retrogresión hitleriana desde el punto de vista de la norma de economía cultural, véase Herman Dooyeweerd, Las raíces de la cultura occidental, pp. 83-89. En este respecto es también muy interesante la intromisión del Estado nacionalsocialista en el arte, la cual está documentada por Peter Adam en su El arte del Tercer Reich.
} 
La globalización es una perversión precisamente porque es un proceso de integración mal dirigido, ya que quebranta (entre otras) la norma de la economía cultural. La vulnera en cuanto que pretende la creación de un mercado mundial sin un desarrollo correlativo de otras instituciones mundiales, notablemente un Estado mundial. Pero también la viola en cuanto que el movimiento del capital financiero no está acompañado con un movimiento correlativo del capital en bienes y servicios. Como señala Goudzwaard, sólo cinco por ciento de las transferencias internacionales de dinero tienen el propósito de comprar o vender bienes o servicios no financieros. $^{23}$

La solución que los globalifóbicos proponen a estos problemas es netamente "anabaptista": cerrar las fronteras e impedir el proceso de integración mundial. La respuesta a esto es que ello es imposible porque constituiría otra violación del orden nómico, el cual conduce a la humanidad hacia la integración en todos los aspectos. Ésta es la razón fundamental por la que los reaccionarios proyectos de clausura étnica (como el del EZLN) o el nacionalismo a ultranza están condenados al fracaso final. Más bien, lo que se requiere es redirigir el proceso de integración.

El sujeto social a cargo de redirigir el proceso debe ser una humanidad crecientemente consciente de la Ley y además responsable. El proceso debe ser redirigido hacia una integración mundial armónica, que respete en general las normas supraarbitrarias y en particular la norma de economía cultural, que genere un mercado mundial responsable con la justicia y el medio ambiente. Los mercados no son, en efecto, mecanismos ciegos, sino instituciones que deben ser construidas de manera responsable y consciente. Para dar una imagen concreta del significado de esta aseveración, considérese una comunidad que comparte una montaña boscosa y un valle agrícola. Un mercado responsable consistiría en una división social del trabajo entre agricultores, cazadores y preservadores del bosque. Los preservadores del bosque tienen por tarea cuidarlo para que pueda haber recarga de mantos freáticos y caza abundante; los cazadores no cazan más de lo que permite la recuperación y reproducción apropiada de las especies; los agricultores usan el agua para producir granos y hortalizas para los cazadores y los preservadores del bosque. Todos reciben una porción del producto total y los precios reflejan las relaciones sociales que hacen posible la sustentabilidad del sistema. Esto requiere - quiérase o no- una actitud reproductiva responsable que permita reemplazar a los individuos sin presionar más los recursos naturales. Éste no es un ejemplo utópico sino demostrablemente factible y se puede dar en la realidad, aunque difícilmente gracias a un supuesto automatismo de los mercados.

${ }^{23}$ Bob Goudzwaard, Globalization and the Kingdom of God, p. 23. 
La elección de un sistema de necesidades es un problema de elección social, pero - en contra del neoliberalismo - esta elección no se puede hacer meramente sobre la base de "preferencias individuales" despojadas de todo sentido de las normas supraarbitrarias. Las preferencias de la gente también están sujetas a normas y deben ser apropiadamente redirigidas. La reforma de la vida involucra también la transformación de los hábitos y las preferencias de las personas.

En particular, para entender la discordancia entre el movimiento del capital financiero y el movimiento de bienes y servicios a nivel internacional (o local) se hace menester un retorno a la teoría del valor trabajo. En efecto, es de suyo evidente que las ganancias especulativas del capital financiero se basan en sistemas de precios que no están "amarrados" a la producción. La teoría del valor trabajo nos dice cuáles son los precios "reales" que deben regir en el mercado para soportar cierta distribución del producto social una vez que el sistema de necesidades ha sido fijado. No es que el valor de los bienes y servicios sea una "cantidad congelada de trabajo social", sino que los valores son precios normativos (precios sombra) que se determinan una vez fijadas las reglas sociales (ponderaciones) de asignación del producto social a los productores. Insistir ad náuseam en que dichas reglas se fijan por el mismo "mercado" es poner nuevamente la causalidad de determinación de los precios en las preferencias individuales, pero las preferencias individuales pueden ser inducidas de manera que transgredan una función normativa que puede parecer razonable incluso a la mayoría. Mi propuesta pone las cosas al derecho: las preferencias individuales deben ser cultivadas y reformadas de manera que se adecuen a una función normativa "racional" (que se ajuste a las normas supraarbitrarias), y se deben crear hábitos, por ejemplo, de justicia social, que impidan reglas injustas de distribución del producto social. Esto determina los precios "reales" en un sentido científicamente preciso. ${ }^{24}$

En el límite, el capital financiero debe reflejar el movimiento de los procesos de producción de bienes y servicios en su totalidad. Cuando ello ocurre, la tasa de interés se aproxima a la tasa de ganancia de las empresas. ${ }^{25}$ Pero ello requiere, por supuesto, que el crédito esté respaldado por la producción misma; esto es, el valor total del crédito en un periodo determinado no debe superar el valor de la producción en ese mismo periodo. Me parece que esta norma debe permitir replantear el problema del riesgo moral en la concesión de créditos: los bancos prestamistas deben asumir parte de la responsabilidad cuando los créditos se vuelven impagables, pues deben prestar solamente cantidades que tengan un respaldo bastante

${ }^{24}$ Véanse los detalles en mi artículo "La medición del trabajo abstracto".

${ }^{25}$ Para una demostración, véase mi libro The Logical Foundations of the Marxian Theory of Value, pp. 173-174. Véase también John E. Roemer, Analytical Foundations of Marxian Economic Theory, pp. 71-86. 
cierto en el proceso de producción. La deuda del Tercer Mundo que no sea pagadera con bienes y servicios, de modo que permita una apropiada reproducción del sistema, representa créditos perdidos y su pérdida debe ser asumida por quienes los otorgaron. Deudas nacionales que impiden la integración armoniosa de las naciones deudoras al mercado mundial representan créditos perdidos.

También para reflejar el movimiento de los procesos de producción de bienes y servicios en su totalidad, a nivel internacional, las transferencias de dinero deben ir pegadas a las transferencias de bienes y servicios. Como el mismo George Soros ha reconocido, el desorden que prevalece en los mercados financieros mundiales (del cual él se ha beneficiado como ninguno) no puede continuar indefinidamente. El dinero virtual debe desaparecer para dar lugar al dinero que carga en sí bienes y servicios.

Parte importante en el reordenamiento de los mercados financieros la tiene que desempeñar un órgano regulador internacional. De manera democrática e inclusiva, el mundo se tiene que ir moviendo hacia un Estado global que asuma funciones de regulación análogas a las que los gobiernos nacionales llevan (o debieran llevar) a cabo internamente en sus respectivos países. Pero ninguna institución internacional o global puede sustituir la responsabilidad de los humanos en su respuesta obediente a la Ley.

\section{BIBLIOGRAFÍA}

Adam, Peter, El arte del Tercer Reich, Tusquets, Barcelona, 1992.

Arrow, Kenneth J., Social Choice and Individual Values, Yale University Press, New Haven, 1963.

Caldwell, Bruce y Stephan Boehm (comps.), Austrian Economics: Tensions and New Developments, Kluwer, Dordrecht, 1992.

Clouser, Roy A., The Myth of Religious Neutrality, University of Notre Dame Press, Notre Dame, 1991.

_-, "A Critique of Historicism", Crítica. Revista Hispanoamericana de Filosofía, vol. XXIX, no. 85, abril de 1997, pp. 41-63.

Condorcet, Marie Jean Antoine Nicolas, marqués de, Esquisse d'un tableau historique des progrès de l'esprit humain, J. Vrin, París, 1970.

Dilworth, Craig (comp.), Intelligibility in Science, Poznan Studies in the Methodology of the Sciences and the Humanities, no. 25, Rodopi, Amsterdam, 1992.

Dooyeweerd, Herman, A Christian Theory of Social Institutions, The Herman Dooyeweerd Foundation, La Jolla, 1986.

_- A New Critique of Theoretical Thought, Paideia, Jordan Station, 1984.

_- Las raíces de la cultura occidental, CLIE, Barcelona, 1998.

García de la Sienra, Adolfo, The Logical Foundations of the Marxian Theory of Value, Kluwer, Dordrecht, 1992.

_ - "Modal Order and Natural Kinds", en Strauss y Botting (comps.), Contemporary Reflections on the Philosophy of Herman Dooyeweerd, pp. 147-155.

__, "La dialéctica del realismo interno", Diánoia, vol. 38, 1992, pp. 95-105. 
García de la Sienra, Adolfo, "La medición del trabajo abstracto", Economía Mexicana, vol. 5, 1996, pp. 63-75.

__, "Reformational Economic Theory", Philosophia Reformata, vol. 66, 2001, pp. 70-83.

_-, "A New Agenda for Economic Theory", en Bob Goudzwaard, Globalization and the Kingdom of God, pp. 83-96.

Goudzwaard, Bob, Globalization and the Kingdom of God, Baker Books/The Center for Public Justice, Grand Rapids y Washington, 2001.

Habermas, Jürgen, Teoría de la acción comunicativa, trad. M. Jiménez Redondo, Taurus, Madrid, 1999.

Hurtado, Guillermo, "La incoherencia del realismo interno", Diánoia, vol. 39, 1993, pp. 119-135.

Iggers, George G. (comp.), The German Conception of History: The National Tradition of Historical Thought from Herder to the Present, Wesleyan University Press, Middleton, 1983.

Jaeger, Werner, La teología de los primeros filósofos griegos, Fondo de Cultura Económica, México, 1992.

Johansson, Igvar, Ontological Investigations, Routledge, Londres, 1989.

Mäki, Uskali, "On the Method of Isolation in Economics", en Craig Dilworth, Intelligibility in Science, pp. 319-354.

_- "The Market as an Isolated Causal Process: A Metaphysical Ground for Realism", en Caldwell y Boehm (comps.), Austrian Economics: Tensions and New Developments, pp. 35-59.

McCarthy, George E., Marx and the Ancients, Rowman and Littlefield, Savage, 1990.

Mirowski, Philip, More Heat than Light. Economics as Social Physics, Physics as Nature's Economics, Cambridge University Press, Cambridge, 1989.

O'Rourke, James, The Problem of Freedom in Marxist Thought: An Analysis of the Treatment of Human Freedom by Marx, Engels, Lenin, and Contemporary Soviet Philosophy, Reidel, Dordrecht, 1974.

Rabossi, Eduardo y Fernando Salmerón (comps.), Ética y análisis I, Instituto de Investigaciones Filosóficas-UNAM, México, 1985.

Roemer, John E., Analytical Foundations of Marxian Economic Theory, Cambridge University Press, Cambridge, 1981.

Searle, John R., "Cómo derivar 'debe' de 'es'”, en Rabossi y Salmerón, Ética y análisis I, pp. 225-242.

Stafleu, Marinus, D., "The Idionomy of Natural Kinds and the Biological Concept of a Species", en Philosophia Reformata, vol. 65, 2000, pp. 154-169.

Strauss, Daniel F.M. y Michelle Botting (comps.), Contemporary Reflections on the Philosophy of Herman Dooyeweerd, The Edwin Mellen Press, Lewiston/Queenston/Lampeter, 2000.

Recibido el 19 de febrero de 2002; revisado el 17 de febrero de 2003; aceptado el 25 de febrero de 2003 